\title{
RESEARCH
}

Open Access

\section{Poorer mental health and sleep quality are associated with greater self-reported reward-related eating during pregnancy and postpartum: an observational cohort study}

Grace M. Betts ${ }^{1}$, Leah M. Lipsky ${ }^{1 *}$ (D) Chelsie D. Temmen ${ }^{1}$, Anna Maria Siega-Riz², Myles S. Faith ${ }^{3}$ and Tonja R. Nansel ${ }^{1}$

\begin{abstract}
Background: Depression, stress, and poor-quality sleep are common during pregnancy and postpartum, but the relationship of these factors with reward-related eating is not well understood. This observational cohort study examines associations of depression, stress, and sleep quality with self-reported reward-related eating in pregnancy and postpartum.

Methods: Participants were enrolled at $<12$ weeks gestation and followed through 1 year postpartum. Selfreported measures obtained at baseline and 23-31 weeks postpartum included the Edinburgh Postnatal Depression Scale, Perceived Stress Scale, Pittsburgh Sleep Quality Index; reward-related eating measures included the Power of Food Scale (assessing hedonic hunger), modified Yale Food Addiction Scale (assessing addictive-like eating), and frequency and intensity of cravings. Linear and logistic regression models estimated associations of depressive symptoms, stress, and sleep quality with reward-related eating during pregnancy and postpartum, as well as change in each predictor with change in outcome.

\footnotetext{
* Correspondence: lipskylm@mail.nih.gov

'Social and Behavioral Sciences Branch, Division of Intramural Population Health Research, Eunice Kennedy Shriver National Institute of Child Health and Human Development, 6710B Rockledge Dr., MSC 7004, Bethesda, MD 20892, USA

Full list of author information is available at the end of the article
}

C C The Author(s). 2021 Open Access This article is licensed under a Creative Commons Attribution 4.0 International License, which permits use, sharing, adaptation, distribution and reproduction in any medium or format, as long as you give appropriate credit to the original author(s) and the source, provide a link to the Creative Commons licence, and indicate if changes were made. The images or other third party material in this article are included in the article's Creative Commons licence, unless indicated otherwise in a credit line to the material. If material is not included in the article's Creative Commons licence and your intended use is not permitted by statutory regulation or exceeds the permitted use, you will need to obtain permission directly from the copyright holder. To view a copy of this licence, visit http://creativecommons.org/licenses/by/4.0/. The Creative Commons Public Domain Dedication waiver (http://creativecommons.org/publicdomain/zero/1.0/) applies to the data made available in this article, unless otherwise stated in a credit line to the data. 
(Continued from previous page)

Results: During pregnancy, greater depressive symptoms $(\beta \pm S E=0.03 \pm 0.01, p<.01)$, higher stress $(0.03 \pm 0.01$, $p<.01)$, and worse sleep quality $(0.03 \pm 0.01, p=0.03)$ were associated with greater hedonic hunger. Similarly, greater depressive symptoms $(\mathrm{OR}=1.08,95 \% \mathrm{Cl}: 1.02,1.14, p=.01)$, higher stress $(\mathrm{OR}=1.09,95 \% \mathrm{Cl}: 1.04,1.14$, $p=<.01)$, and worse sleep quality $(\mathrm{OR}=1.09,95 \% \mathrm{Cl}: 1.00,1.18, p=.04)$ were associated with greater odds of addictive-like eating. These associations were also significant in postpartum except that sleep quality was not associated with hedonic hunger. Greater depressive symptoms $(\beta \pm \mathrm{SE}=0.06 \pm 0.02, p<.01 ; 0.08 \pm 0.02, p=<.01)$, higher stress $(0.04 \pm 0.01, p<.01 ; 0.06 \pm 0.02, p<.01)$, and worse sleep quality $(0.11 \pm 0.03, p<.01 ; 0.13 \pm 0.03, p<.01)$ during pregnancy were associated with stronger and more frequent cravings, respectively. Increased depressive symptoms from pregnancy to postpartum was associated with increased hedonic hunger $(\beta \pm \mathrm{SE}=1.17 \pm 0.57, p=$ $0.01)$ and addictive-like eating $(0.88 \pm 0.33, p=0.01)$, and increased stress was associated with increased hedonic hunger $(1.71 \pm 0.76, p=0.02)$. Change in stress was not associated with change in addictive-like eating and change in sleep quality was not associated with change in either hedonic hunger or addictive-like eating.

Conclusions: Greater depressive symptoms, perceived stress, and poorer sleep quality are associated with greater self-reported reward-related eating during pregnancy and postpartum, suggesting that efforts to improve diet during and after pregnancy may benefit from addressing mental health and sleep.

Trial registration: Clinicaltrials.gov

Registration ID - NCT02217462.

Date of registration - August 13, 2014

Keywords: Depressive symptoms, Perceived stress, Mental health, Sleep quality, Reward-related eating, Pregnancy, Postpartum

\section{Background}

On average, pregnant women do not meet dietary recommendations [1]. Understanding neurobehavioral influences on maternal diet quality may have important implications for improving maternal $[2,3]$ and infant health outcomes [4-6]. In non-pregnant adults greater self-reported sensitivity to reward is associated with more intense and frequent food cravings [7], higher BMI [7, 8], and emotional overeating [8]. Additionally, greater self-reported reward sensitivity is associated with greater activation in reward-related brain areas in response to appetizing food images [9]. Population-based studies have shown positive associations of self-reported reward-related eating with intake of discretionary foods [10] and BMI [11]. Although food cravings are widely reported during pregnancy and are positively associated with discretionary food intake and excessive gestational weight gain [12], little is known about the correlates of reward-related eating in pregnant and postpartum women.

Depression [13, 14], stress [15-17], and insufficient sleep [18] are common during pregnancy and postpartum $[13,16,18]$. Furthermore, neuroimaging studies of nonpregnant adults indicate these factors can impact the functioning of neural circuits known to regulate rewardseeking behavior, motivation, and eating [19-21]. Depressive symptoms are associated with changes in blood flow in brain areas related to motivation, emotion, and appetite [20], structural and functional alterations within the brain's reward circuitry [22], as well as blunted neural response to reward [23]. These alterations have been posited to explain associations of depression with poor food selection (e.g., lower intake of fruits and vegetables and higher intake of fast food and soda) [24, 25], undereating, and compensatory overeating of highly rewarding foods [26]. Depressive symptoms have also been associated with greater motivation to seek out food reward [27] and are significantly higher in individuals with addictive-like eating [28-30]. However, few prospective studies have examined these associations, and none have investigated these relations in pregnant or postpartum women.

Stress may also impact brain reward response and reward-related eating behaviors [21]. Acute stress has been associated with lower neural activity in response to monetary rewards [21] and food rewards [31]. Perceived stress has been associated with greater emotional eating and lower eating competence in overweight women [32], and greater consumption of sweets and salty snacks and lower consumption of fruits and vegetables in healthy adults [33, 34]. Additionally, findings from the Nurses' Health study indicate that addictive-like eating is more prevalent in women with a history of Post-Traumatic Stress Disorder (PTSD) [35] or child abuse [36].

Consistent evidence from experimental neuroimaging studies of nonpregnant healthy adults indicates that sleep deprivation enhances the neural response to food reward [37-39] and non-food reward [19]. Additionally, observational studies show that insufficient sleep is also associated with increased energy intake in healthy men 
and women [40] and increased portion size selection in healthy women [41]. There are likely multiple pathways explaining this association, one hypothesis being that insufficient sleep is associated with greater sensitivity to food reward [42]. However, relationships of stress and sleep with self-reported reward-related eating have not been examined.

The purpose of this study was to address these knowledge gaps by investigating relationships of reward-related eating with depression, stress, and sleep quality in pregnant and postpartum women. We hypothesized that more depressive symptoms, higher perceived stress, and worse sleep quality are associated with higher self-reported reward-related eating during pregnancy and postpartum.

\section{Methods}

\section{Participants and procedures}

Data are from the Pregnancy Eating Attributes Study (PEAS), a longitudinal observational study of women from early pregnancy $(<12$ weeks gestation) to 1 year postpartum [43]. Participants $(n=458)$ were recruited while obtaining prenatal care at University of North Carolina (UNC) at Chapel Hill Women's Hospital. Written informed consent was obtained at recruitment. Enrollment began in October 2014 and continued through October 2016, with the following inclusion criteria: the mother (1) planned to deliver at UNC Women's Hospital (singleton pregnancy expected) and remain in the area through 1 year postpartum, (2) had a BMI $\geq 18.5 \mathrm{~kg} / \mathrm{m} 2$, (3) was between 18 and 45 years old, (4) had the ability to read and write in English, and (5) had access to internet and email. Women were excluded based on the following: multiple pregnancy, participant-reported psychiatric or eating disorder, or pre-existing diabetes or other medical condition contraindicating study participation. Self-report questionnaires were completed online within designated study windows at baseline ( $<12$ weeks gestation), 16-22 weeks, and 28-32 weeks gestation, and postpartum at 4-6 weeks, 6 months, and 12 months. Depressive symptoms, stress, sleep quality, and reward-related eating (addictive-like eating, hedonic hunger, and cravings) were assessed at baseline and 6 months postpartum; cravings and sociodemographic characteristics were assessed at baseline. In person study visits collected data on anthropometrics, and included the collection of biospecimens at various times. Study procedures were approved by the University of North Carolina Institutional Review Board.

\section{Measures}

\section{Depression}

Depression was assessed using the 10-item Edinburgh Postnatal Depression Scale [44]. Example items include, "I have been able to laugh and see the funny side of things" with responses ranging from 0 (as much as I always could) to 3 (not at all). The scale demonstrated strong internal consistency during pregnancy (Cronbach's alpha $=0.84$ ) and postpartum (Cronbach's alpha = .88). Total scores range from 0 to 30 ; higher scores indicate greater depressive symptoms.

\section{Stress}

Stress was assessed using the 10-item Perceived Stress Scale measuring perceived stress over the past month $[45,46]$. Example items include, "In the last month, how often have you felt nervous and 'stressed'?" with Likerttype responses ranging from 0 (never) to 4 (very often). The scale demonstrated strong internal consistency during pregnancy (Cronbach's alpha $=0.89$ ) and postpartum (Cronbach's alpha $=.91)$. Responses to each item are summed to produce a total score ranging from 0 to 40; higher scores indicate higher perceived stress.

\section{Sleep quality}

Sleep quality was assessed using the 9-item Pittsburgh Sleep Quality Index, which covers seven domains of sleep quality: subjective sleep quality, sleep latency, sleep duration, habitual sleep efficiency, sleep disturbances, use of sleep medication, and daytime dysfunction [47]. Items query sleep habits during the past month with most questions asking respondents to report how often they have had trouble sleeping for several reasons. Response options range from "not during the past month" to "three or more times a week." The scale demonstrated strong internal consistency during pregnancy (Cronbach's alpha $=0.74)$ and postpartum (Cronbach's alpha = 75 ). Total scores range from 0 to 21 ; higher scores indicate poorer sleep quality.

\section{Addictive-like eating}

The 9-item modified Yale Food Addiction Scale measures symptoms of addictive-like eating [28]. Seven of the nine items ask participants to report frequency of addictive eating symptoms, such as "I feel sluggish or fatigued from overeating," with responses ranging from 1 (never) to 5 ( $\geq 4$ times/week). Based on the published threshold criterion responses for each symptom are dichotomized as below or meeting threshold. The remaining two items assess the presence of "clinically significant impairment," e.g., "I kept consuming the same types or amounts of food despite significant emotional and/or physical problems related to my eating," with response options yes or no. Responses to the 9 items were coded as 0 (not meeting threshold or negative response) or 1 (meeting threshold or positive response) and summed. Due to highly skewed distribution of responses, scores of $\geq 2$ were collapsed into one group for cross-sectional pregnancy and postpartum analyses. This group accounted for $12 \%$ of participants, with $70 \%$ 
having a score of 0 and $18 \%$ a score of 1 . For calculation of change scores, the full continuous range of scores was used.

\section{Hedonic hunger}

The 15-item Power of Food Scale [48] measures hedonic hunger, conceptualized as the psychological appetitive response to environmental food cues. Questions include, "I find myself thinking of food even when I'm not physically hungry," and "If I see or smell a food I like, I get a powerful urge to have some," with responses rated on a 5-point Likert scale from 1 (don't agree at all) to 5 (strongly agree). The scale demonstrated strong internal consistency during pregnancy (Cronbach's alpha $=0.88$ ) and postpartum (Cronbach's alpha $=.92$ ). Total scores range from 1 to 5 and are calculated as the mean of three component scores, which are calculated from the mean of the corresponding items. Higher scores indicate greater hedonic hunger.

\section{Cravings}

Food cravings were assessed using items developed by the study investigators, given the lack of an existing validated measure in pregnant women. The measure allowed participants to list their most craved foods, rather than responding to a predefined list, and enabled the assessment of both the frequency and intensity of overall and specific food cravings. One item asked, "In the past month, have you ever had a craving or strong desire to eat or drink a food or beverage such that you simply could not resist consuming the item?" If the answer was yes, participants listed up to three foods or beverages craved, and then rated the craving frequency, ranging from 1 (never) to 5 (very frequently), and strength, ranging from 1 (mild) to 5 (strongest imaginable). Craving frequency and intensity were calculated as the highest response across foods.

\section{Covariates}

Variables hypothesized to be causally related to the predictors and outcomes of interest, based on a review of literature, were considered as confounders. Participants self-reported demographic information including age, marital status, education, household income, and household size at baseline. Marital status was categorized as either married or not married. Education was categorized as less than a bachelor's degree, bachelor's degree, or graduate degree. Income-poverty ratio was calculated as the ratio of household income relative to the poverty threshold according to household size [49] with higher values indicating greater income relative to the poverty threshold.

\section{Analysis}

Data were analyzed using SAS software Version 9.4 [50]. Pearson correlations estimated bivariate associations among the main exposures and outcomes in pregnancy and postpartum, with the Sidak method used to adjust for multiple comparisons. General linear regression models were used to analyze continuous outcomes (hedonic hunger and cravings); ordered logistic regression models were used to analyze ordinal outcomes (addictive-like eating). Separate models were used to investigate relationships with each of the independent variables of interest (depressive symptoms, stress, and sleep quality) during pregnancy and during postpartum. Age, marital status, education, and income-to poverty ratio were included as covariates for all models. Paired t-tests examined changes in the main exposures and outcomes from early pregnancy to 6 months postpartum. General linear regression models examined whether change in each predictor (calculated by subtracting the pregnancy from the postpartum score) was associated with change in reward-related eating. Baseline scores for each variable were included in the models along with the covariates indicated above.

\section{Results}

Of the 458 women enrolled, 91 (20\%) withdrew prior to delivery and $46(10 \%)$ withdrew or were lost to followup during postpartum. Women with available data on at least one predictor or outcome were included in the analysis $(N=373)$. Those included were on average 1.8 years older $(1.78 \pm 0.56, \mathrm{p}=<.01)$ with a baseline BMI 2.9 points lower $(-2.93 \pm 0.94, \mathrm{p}=<.01)$ than those not included. The majority of the participants were over 30 , non-Hispanic white, married, and had at least a bachelor's degree (Table 1).

As shown in Table 2, during pregnancy, depressive symptoms, stress, and sleep quality were each positively correlated with one or more measures of reward-related eating. Similar correlations were observed during

Table 1 Sample Demographic Characteristics

\begin{tabular}{lll}
\hline Variable & $\mathbf{N}$ & Mean \pm SD or N (\%) \\
\hline Age & 373 & $30.79 \pm 4.58$ \\
Marital status & 373 & \\
Married & & $324(91.8 \%)$ \\
Not married & & $29(8.2 \%)$ \\
Education & 353 & \\
Less than a bachelor's degree & & $93(26.4 \%)$ \\
Bachelor's degree & & $107(30.3 \%)$ \\
Graduate degree & & $153(43.3 \%)$ \\
Income-poverty ratio & 350 & $3.92 \pm 1.94$ \\
BMl & 353 & $26.64 \pm 6.55$ \\
\hline
\end{tabular}


Table 2 Bivariate ${ }^{a}$ and descriptive statistics for pregnancy and postpartum

\begin{tabular}{|c|c|c|c|c|c|c|c|c|c|c|c|c|}
\hline & \multirow[t]{2}{*}{1} & \multirow[t]{2}{*}{2} & \multirow[t]{2}{*}{3} & \multirow[t]{2}{*}{4} & \multirow[t]{2}{*}{5} & \multirow[t]{2}{*}{6} & \multirow[t]{2}{*}{7} & \multicolumn{2}{|l|}{ Pregnancy } & \multicolumn{2}{|l|}{ Postpartum } & \multirow[t]{2}{*}{$p^{b}$} \\
\hline & & & & & & & & Mean (SD) & $\mathbf{N}$ & Mean (SD) & $\mathbf{N}$ & \\
\hline 1. Depressive Symptoms & - & $.81 * *$ & $.48^{* *}$ & .22 & $.24^{*}$ & - & - & $5.05(4.11)$ & 328 & $5.09(4.44)$ & 205 & 0.09 \\
\hline 2. Stress & $.62^{* *}$ & - & $.44^{* *}$ & $.29 * *$ & $.27^{* *}$ & - & - & $13.85(6.25)$ & 310 & $14.46(6.67)$ & 207 & 0.053 \\
\hline 3. Sleep Quality & $.50^{* *}$ & $.44^{* *}$ & - & .08 & .22 & - & - & $5.67(3.22)$ & 294 & $6.17(3.41)$ & 207 & $<.001$ \\
\hline 4. Hedonic Hunger & .18 & $.25^{* *}$ & $.14^{*}$ & - & $.38^{* *}$ & - & - & 2.19 (0.69) & 353 & $2.25(0.76)$ & 227 & 0.06 \\
\hline 5. Addictive-like Eating ${ }^{c}$ & .18 & .18 & $.20^{*}$ & $.31^{* *}$ & - & - & - & $0.43(0.70)$ & 344 & $0.41(0.70)$ & 217 & 0.71 \\
\hline 6. Cravings (Frequency) & .18 & .19 & $.23^{* *}$ & $.20^{*}$ & .07 & - & - & $2.68(1.51)$ & 334 & - & - & - \\
\hline 7. Cravings (Strength) & $.21^{*}$ & $.23^{* *}$ & $.24^{* *}$ & $.22^{* *}$ & .08 & $.93^{* *}$ & - & $1.95(1.77)$ & 334 & - & - & - \\
\hline
\end{tabular}

Note: Italicized values are for pregnancy; bolded values are for postpartum. ${ }^{*} p<.05 ;{ }^{* *} \mathrm{p}<.01$

a Sidak method was used to adjust for multiple comparisons

${ }^{\mathrm{b}}$ Paired t-test from pregnancy to postpartum

${ }^{c}$ Modified Yale Food Addiction Scale is used continuously here to reflect changes occurring above a score of 2

postpartum, except that sleep quality was not correlated with either measure of reward-related eating. Depression $(\mathrm{M} \pm \mathrm{SD}$ of change $=0.52 \pm 4.19)$, stress $(0.80 \pm 3.49)$, sleep quality $(0.93 \pm 3.49)$, and hedonic hunger $(0.07 \pm$ 0.52 ) increased from pregnancy to postpartum, but only the change in sleep quality $(p<.001)$ was statistically significant. Addictive-like eating did not change from pregnancy to postpartum $(-0.02 \pm 0.94, p=0.71)$.

In regression analyses controlling for covariates, greater depressive symptoms, perceived stress, and worse sleep quality were associated with greater endorsement of hedonic hunger and addictive-like eating, and more frequent and intense cravings during pregnancy (Table 3). During postpartum, greater depressive symptoms and perceived stress were associated with greater endorsement of hedonic hunger and addictive-like eating. Worse sleep quality was associated with greater endorsement of addictive-like eating, but not with hedonic hunger.

Depressive symptoms, perceived stress and hedonic hunger were modestly higher in postpartum than pregnancy, although differences were not statistically significant (Table 2). Change in depressive symptoms from pregnancy to postpartum was positively associated with change in hedonic hunger and addictive-like eating
(Table 4). Change in perceived stress was positively associated with change in hedonic hunger, but not addictive-like eating, and change in sleep quality was not associated with change in hedonic hunger or addictivelike eating.

\section{Discussion}

In this cohort of women followed from early pregnancy through postpartum, greater depressive symptoms, higher stress, and worse sleep quality were crosssectionally associated with greater reward-related eating during pregnancy, as indicated by addictive-like eating, hedonic hunger, and the strength and frequency of cravings. Findings were similar during postpartum, except that sleep quality was not associated with hedonic hunger. In prospective analyses, changes in depressive symptoms and stress from pregnancy to postpartum were associated with changes in some indicators of rewardrelated eating. In contrast, sleep quality decreased from pregnancy to postpartum, but this change was not associated with change in reward-related eating. Overall, depressive symptoms and stress were cross-sectionally and prospectively associated with reward-related eating, while sleep quality was associated with reward-related eating only in cross-sectional analyses. Effect sizes were

Table 3 Associations of depression, stress, and sleep quality with reward-related eating and cravings

\begin{tabular}{|c|c|c|c|c|c|c|c|c|c|c|c|c|}
\hline & & \multicolumn{3}{|c|}{ Hedonic Hunger } & \multicolumn{3}{|c|}{ Addictive-Like Eating } & \multicolumn{2}{|c|}{ Cravings (Frequency) } & \multicolumn{3}{|c|}{ Cravings (Strength) } \\
\hline & & $\beta(S E)$ & $p$ & $N$ & OR (95\% CI) & $p$ & $N$ & $\beta(S E)$ & $p$ & $\beta(S E)$ & $p$ & $N$ \\
\hline \multirow[t]{3}{*}{ Pregnancy } & Depressive Symptoms & $0.03(.01)$ & $<.01$ & 313 & $1.08(1.02,1.14)$ & .01 & 313 & $0.06(0.02)$ & $<.01$ & $0.08(0.02)$ & $<.01$ & 309 \\
\hline & Stress & $0.03(.01)$ & $<.01$ & 285 & $1.09(1.04,1.14)$ & $<.01$ & 298 & $0.04(0.01)$ & $<.01$ & $0.06(0.02)$ & $<.01$ & 274 \\
\hline & Sleep Quality & $0.03(.01)$ & .03 & 280 & $1.09(1.00,1.18)$ & .04 & 278 & $0.11(0.03)$ & $<.01$ & $0.13(0.03)$ & $<.01$ & 277 \\
\hline \multirow[t]{3}{*}{ Postpartum } & Depressive Symptoms & $0.03(.01)$ & .01 & 195 & $1.11(1.03,1.19)$ & $<.01$ & 193 & - & - & - & - & \\
\hline & Stress & $0.03(.01)$ & $<.01$ & 197 & $1.09(1.04,1.15)$ & $<.01$ & 195 & - & - & - & - & \\
\hline & Sleep Quality & $0.02(.02)$ & .35 & 199 & $1.13(1.03,1.23)$ & .01 & 196 & - & - & - & - & \\
\hline
\end{tabular}

Note: Unstandardized estimates are reported. Linear and ordered logistic regression models adjusted for age, marital status, education, and income-to poverty ratio 
Table 4 Associations of change in depression, stress, and sleep quality with change in reward-related eating

\begin{tabular}{|c|c|c|c|c|c|c|}
\hline & \multicolumn{3}{|c|}{$\Delta$ Hedonic Hunger } & \multicolumn{3}{|c|}{$\begin{array}{l}\Delta \text { Addictive-Like } \\
\text { Eating }\end{array}$} \\
\hline & $\beta$ (SE) & $p$ & $\mathbf{N}$ & $\beta(\mathrm{SE})$ & $p$ & $\mathrm{~N}$ \\
\hline$\Delta$ Depressive Symptoms & $0.02(0.01)$ & .04 & 182 & $0.04(0.02)$ & .01 & 180 \\
\hline$\Delta$ Stress & $0.02(0.01)$ & .02 & 183 & $0.02(0.01)$ & .07 & 179 \\
\hline$\triangle$ Sleep Quality & $-0.002(0.01)$ & .86 & 168 & $0.009(0.02)$ & .68 & 167 \\
\hline
\end{tabular}

Note: Unstandardized estimates are reported. Linear regression models adjusted for baseline predictor score, age, marital status, education, and income-to poverty ratio

small but consistent across models, suggesting that these constructs are among multiple drivers of reward-related eating.

The positive associations of depressive symptoms and stress with reward-related eating and cravings observed in this study are consistent with previous studies in nonpregnant samples. Greater depressive symptoms [28-30] and trauma-related stress [35, 36] were associated with greater addictive-like eating as measured by the Yale Food Addiction Scale. Stress and psychological distress have also been associated with lower intake of fruits and vegetables and higher intake of high-fat and high-sugar foods in experimental and observational studies [24, 25]. Further, cravings were positively associated with anxiety and dysphoric mood [51] and the severity of depression [52]. Neuroimaging research shows that depressive symptoms are associated with blunted neural reward response [23], alterations within the brain's reward circuitry [22], and changes in blood flow to areas of the brain related to motivation and appetite [20], providing a plausible physiological mechanism for associations of depressive symptoms with reward-related eating. A subset of women in the PEAS cohort participating in a focus group sub-study during their second trimester indicated that positive and negative moods often preceded food cravings [53], consistent with the current quantitative findings. The positive associations of depressive symptoms and stress with reward-related eating found in the present study are consistent with the hypothesis that reward-seeking is a compensatory behavior for the blunted neural response to reward that occurs in depression [26] and under stressed conditions [21, 31].

As reported herein, in prospective analyses, increased depressive symptoms from pregnancy to postpartum was associated with increased hedonic hunger and addictive-like eating. In contrast, while stress was positively associated with addictive-like eating and hedonic hunger in cross-sectional analyses, increased stress was prospectively associated only with increased addictive-like eating. The longitudinal association of stress with addictive-like eating is consistent with those from a retrospective study of women finding associations of trauma-related stress in childhood with addictive-like eating in adulthood $[35,36]$. The null prospective association of stress with hedonic hunger suggests that the positive crosssectional association could be due to confounding. Intervention studies are needed to clarify whether reducing depressive symptoms or stress impacts reward-based eating behaviors.

In this study, worse sleep quality was cross-sectionally associated with greater hedonic hunger, addictive-like eating, and food cravings during pregnancy, and greater addictive-like eating, but not hedonic hunger, during postpartum. These findings are largely consistent with previous research in nonpregnant samples finding positive associations of shorter sleep duration with food cravings [41, 54], appetite or hunger for energy-dense foods [41, 55], and neural activation in response to food stimuli, especially high-energy foods [37-39]. They are also consistent with research demonstrating that sleep restriction increases circulating concentrations of endocannabinoids (which are involved in the control of appetite and energy homeostasis) and concomitant reports of hunger and appetite [56]. The lack of association between sleep quality and hedonic hunger during postpartum suggests the relationship may be impacted by pregnancy status, and merits further investigation. It may also reflect the differences in the severity of rewardrelated eating represented by measures of addictive-like eating and hedonic hunger. Despite significant crosssectional associations, and declines in sleep quality from pregnancy to postpartum, change in sleep quality was not prospectively associated with change in hedonic hunger or addictive-like eating. The lack of a prospective association could be due to the large proportion (40\%) of women in this study whose sleep quality either did not change or changed by only 1 point from pregnancy to postpartum, which limits the power to detect associations between changes in sleep quality and rewardrelated eating.

Interpretation of these findings should consider the strengths and limitations of this study. Participants were recruited from a single location in the Southeastern United States with limited racial/ethnic and socioeconomic diversity, potentially limiting generalizability. However, the sample reflects the geographical area that is majority white with a bachelor's degree or higher and with a median household income of $\$ 68,640$ [57]. While sleep was assessed using self-report measures that are more susceptible to response bias than objective measures, the large sample size, measurement of and adjustment for covariates, as well as the use of validated measures of sleep quality, perceived stress, and depressive symptoms, and multiple self-report measures of reward-related eating strengthen the internal validity of 
the findings. Additionally, the prospective study design precludes recall bias and provides evidence for a temporal relationship between the variables of interest.

\section{Conclusions}

In conclusion, depressive symptoms, perceived stress, and sleep quality were associated with multiple measures of reward-related eating during pregnancy and postpartum. Increased depressive symptoms and stress were associated with increased reward-related eating from pregnancy to postpartum, but no association was observed with change in sleep quality. Given the associations of reward-related eating with unhealthy food choices $[58,59]$ and increased intake of discretionary foods $[10,60,61]$, these findings suggest the need to examine whether targeting mental health and sleep quality improves eating behaviors in women during pregnancy and postpartum. Assessing sleep quality and mental health may assist healthcare professionals counseling women on healthful eating.

\section{Abbreviations}

PEAS: Pregnancy Eating Attributes Study; BMI: Body mass index

\section{Supplementary Information}

The online version contains supplementary material available at https://doi. org/10.1186/s12966-021-01124-9.

\section{Additional file 1.}

Additional file 2 .

\section{Acknowledgements}

Not applicable.

\section{Authors' contributions}

All authors designed research; AMSR and MF acquired data, GB and CT analyzed data, all authors wrote paper; GB, LL, and TN had primary responsibility for final content. All authors read and approved the final manuscript.

\section{Funding}

This research was supported by the Eunice Kennedy Shriver National Institute of Child Health and Human Development Intramural Research Program (contract \#HHSN275201300012C and \#HHSN2752013000261/HHSN27500002). The funding body had no role in the study design; collection, analysis, and interpretation of data; or writing the manuscript. Open Access funding provided by the National Institutes of Health $(\mathrm{NIH})$.

\section{Availability of data and materials}

The datasets used and/or analyzed during the current study are available from the corresponding author on reasonable request. Following publication of study objectives, de-identified data will be shared in the NICHD Data and Specimen Hub.

\section{Declarations}

\section{Ethics approval and consent to participate}

Study procedures were approved by the University of North Carolina Institutional Review Board, IRB \#: 13-3848. Written informed consent was obtained from all participants.

\section{Consent for publication}

Not applicable.

\section{Competing interests}

The authors declare that they have no competing interests.

\section{Author details}

${ }^{1}$ Social and Behavioral Sciences Branch, Division of Intramural Population Health Research, Eunice Kennedy Shriver National Institute of Child Health and Human Development, 6710B Rockledge Dr., MSC 7004, Bethesda, MD 20892, USA. ${ }^{2}$ Departments of Nutrition and Biostatistics and Epidemiology, School of Public Health and Health Sciences, University of Massachusetts, 109 Arnold House, 715 Pleasant St, Amherst, MA 01003-9303, USA.

${ }^{3}$ Department of Counseling, School, and Educational Psychology, Graduate School of Education, 420 Baldy Hall, University at Buffalo - SUNY, Buffalo, NY 14250-1000, USA.

Received: 9 October 2020 Accepted: 19 April 2021

Published online: 01 May 2021

\section{References}

1. Bodnar LM, Simhan HN, Parker CB, Meier H, Mercer BM, Grobman WA, et al. Racial or Ethnic and Socioeconomic Inequalities in Adherence to National Dietary Guidance in a Large Cohort of US Pregnant Women. J Acad Nutr Diet. 2017:117(6):867-77 e3.

2. Olson CM, Strawderman MS. Modifiable behavioral factors in a biopsychosocial model predict inadequate and excessive gestational weight gain. J Am Diet Assoc. 2003;103(1):48-54. https://doi.org/10.1053/jada.2003. 50001.

3. Shin D, Lee KW, Song WO. Dietary patterns during pregnancy are associated with risk of gestational diabetes mellitus. Nutrients. 2015;7(11):9369-82. https://doi.org/10.3390/nu7115472

4. Gluckman PD, Hanson MA, Cooper C, Thornburg KL. Effect of in utero and early-life conditions on adult health and disease. N Engl J Med. 2008;359(1): 61-73. https://doi.org/10.1056/NEJMra0708473.

5. Harding JE. The nutritional basis of the fetal origins of adult disease. Int J Epidemiol. 2001;30(1):15-23. https://doi.org/10.1093/ije/30.1.15.

6. Shapiro AL, Kaar JL, Crume TL, Starling AP, Siega-Riz AM, Ringham BM, et al. Maternal diet quality in pregnancy and neonatal adiposity: the Healthy Start Study. Int J Obesity (2005). 2016:40(7):1056-62.

7. Franken $\mathbb{H}$, Muris $\mathrm{P}$. Individual differences in reward sensitivity are related to food craving and relative body weight in healthy women. Appetite. 2005; 45(2):198-201. https://doi.org/10.1016/j.appet.2005.04.004.

8. Davis C, Strachan S, Berkson M. Sensitivity to reward: implications for overeating and overweight. Appetite. 2004;42(2):131-8. https://doi.org/10.1 016/j.appet.2003.07.004.

9. Beaver JD, Lawrence AD, Van Ditzhuijzen J, Davis MH, Woods A, Calder AJ. Individual differences in reward drive predict neural responses to images of food. J Neurosci. 2006;26(19):5160-6. https://doi.org/10.1523/JNEUROSCI.03 50-06.2006

10. Nansel TR, Lipsky LM, Eisenberg MH, Haynie DL, Liu DP, Simons-Morton B. Greater food reward sensitivity is associated with more frequent intake of discretionary foods in a nationally representative sample of young adults. Front Nutrition. 2016:3:6

11. Epel ES, Tomiyama AJ, Mason AE, Laraia BA, Hartman W, Ready K, et al. The reward-based eating drive scale: a self-report index of reward-based eating. PLoS One. 2014;9(6):e101350. https://doi.org/10.1371/journal.pone.0101350.

12. Orloff NC, Flammer A, Hartnett J, Liquorman S, Samelson R, Hormes JM. Food cravings in pregnancy: preliminary evidence for a role in excess gestational weight gain. Appetite. 2016;105:259-65. https://doi.org/10.1016/ j.appet.2016.04.040.

13. Bennett HA, Einarson A, Taddio A, Koren G, Einarson TR. Prevalence of depression during pregnancy: systematic review. Obstet Gynecol. 2004; 103(4):698-709. https://doi.org/10.1097/01.AOG.0000116689.75396.5f.

14. Pampaka D, Papatheodorou SI, AlSeaidan M, Al Wotayan R, Wright RJ, Buring JE, et al. Depressive symptoms and comorbid problems in pregnancy - results from a population based study. J Psychosom Res. 2018; 112:53-8. https://doi.org/10.1016/j.jpsychores.2018.06.011.

15. Kingston D, Heaman M, Fell D, Dzakpasu S, Chalmers B. Factors associated with perceived stress and stressful life events in pregnant women: findings from the Canadian maternity experiences survey. Matern Child Health J. 2012;16(1):158-68. https://doi.org/10.1007/s10995-010-0732-2.

16. Ayers S, Crawley R, Webb R, Button S, Thornton A, group HAc. What are women stressed about after birth? Birth. 2019;46(4):678-85. 
17. Woods SM, Melville JL, Guo Y, Fan MY, Gavin A. Psychosocial stress during pregnancy. Am J Obstet Gynecol. 2010;202(1):61 e1-7.

18. Christian LM, Carroll JE, Porter K, Hall MH. Sleep quality across pregnancy and postpartum: effects of parity and race. Sleep Health. 2019;5(4):327-34. https://doi.org/10.1016/j.sleh.2019.03.005.

19. Gujar N, Yoo SS, Hu P, Walker MP. Sleep deprivation amplifies reactivity of brain reward networks, biasing the appraisal of positive emotional experiences. J Neurosci. 2011;31(12):4466-74. https://doi.org/10.1523/ JNEUROSCI.3220-10.2011.

20. Nestler EJ, Barrot M, DiLeone RJ, Eisch AJ, Gold SJ, Monteggia LM. Neurobiology of depression. Neuron. 2002;34(1):13-25. https://doi.org/10.1 016/50896-6273(02)00653-0.

21. Porcelli AJ, Lewis AH, Delgado MR. Acute stress influences neural circuits of reward processing. Front Neurosci. 2012;6:9.

22. Russo SJ, Nestler EJ. The brain reward circuitry in mood disorders. Nat Rev Neurosci. 2013;14(9):609-25. https://doi.org/10.1038/nrn3381.

23. Epstein J, Pan H, Kocsis JH, Yang Y, Butler T, Chusid J, et al. Lack of ventral striatal response to positive stimuli in depressed versus normal subjects. Am J Psychiatry. 2006;163(10):1784-90. https://doi.org/10.1176/ajp.2006.163.10.1 784

24. Yau YHC, Potenza MN. Stress and eating behaviors. Minerva Endocrinol. 2013;38(3):255-67.

25. Banta JE, Segovia-Siapco G, Crocker CB, Montoya D, Alhusseini N. Mental health status and dietary intake among California adults: a population-based survey. Int J Food Sci Nutr. 2019;70(6):759-70. https://doi.org/10.1080/0963 7486.2019 .1570085 .

26. Singh M. Mood, food, and obesity. Front Psychol. 2014;5:20.

27. Fussner LM, Mancini KJ, Luebbe AM. Depression and approach motivation: differential relations to monetary, social, and food reward. J Psychopathol Behav Assess. 2018;40(1):117-29. https://doi.org/10.1007/s10862-017-9620-z.

28. Flint AJ, Gearhardt AN, Corbin WR, Brownell KD, Field AE, Rimm EB. Foodaddiction scale measurement in 2 cohorts of middle-aged and older women(1-3). Am J Clin Nutr. 2014;99(3):578-86. https://doi.org/10.3945/a jcn.113.068965.

29. Koball AM, Clark MM, Collazo-Clavell M, Kellogg T, Ames G, Ebbert J, et al. The relationship among food addiction, negative mood, and eating-disordered behaviors in patients seeking to have bariatric surgery. Surg Obes Relat Dis. 2016;12(1):165-70. https:/doi.org/10.1016/.jsoard.2015.04.009.

30. Piccinni A, Marazziti D, Cargioli C, Mauri M, Stallone T. Food addiction: is it a nosological category or a psychopathological dimension? Preliminary results of an Italian study. Horm Mol Biol Clin Investig. 2018;36(1):1868-91.

31. Born JM, Lemmens SG, Rutters F, Nieuwenhuizen AG, Formisano E, Goebel $R$, et al. Acute stress and food-related reward activation in the brain during food choice during eating in the absence of hunger. Int J Obesity (2005). 2010;34(1):172-81.

32. Jarvela-Reijonen E, Karhunen L, Sairanen E, Rantala S, Laitinen J, Puttonen S, et al. High perceived stress is associated with unfavorable eating behavior in overweight and obese Finns of working age. Appetite. 2016;103:249-58. https://doi.org/10.1016/j.appet.2016.04.023.

33. Mikolajczyk RT, El Ansari W, Maxwell AE. Food consumption frequency and perceived stress and depressive symptoms among students in three European countries. Nutr J. 2009;8(1):31. https://doi.org/10.1186/1475-2891-8-31.

34. Laugero KD, Falcon LM, Tucker KL. Relationship between perceived stress and dietary and activity patterns in older adults participating in the Boston Puerto Rican health study. Appetite. 2011;56(1):194-204. https://doi.org/10.1 016/j.appet.2010.11.001.

35. Mason SM, Flint AJ, Roberts AL, Agnew-Blais J, Koenen KC, Rich-Edwards JW. Posttraumatic stress disorder symptoms and food addiction in women by timing and type of trauma exposure. JAMA Psychiatry. 2014;71(11):1271-8. https://doi.org/10.1001/jamapsychiatry.2014.1208.

36. Mason SM, Flint AJ, Field AE, Austin SB, Rich-Edwards JW. Abuse victimization in childhood or adolescence and risk of food addiction in adult women. Obesity (Silver Spring). 2013;21(12):E775-81. https://doi.org/1 0.1002/oby.20500

37. Benedict C, Brooks SJ, O'Daly OG, Almen MS, Morell A, Aberg K, et al. Acute sleep deprivation enhances the brain's response to hedonic food stimuli: an fMRI study. J Clin Endocrinol Metab. 2012;97(3):E443-7. https://doi.org/1 $0.1210 / j \mathrm{c} .2011-2759$

38. St-Onge MP, Wolfe S, Sy M, Shechter A, Hirsch J. Sleep restriction increases the neuronal response to unhealthy food in normal-weight individuals. Int J Obesity (2005). 2014;38(3):411-6.
39. St-Onge MP, McReynolds A, Trivedi ZB, Roberts AL, Sy M, Hirsch J. Sleep restriction leads to increased activation of brain regions sensitive to food stimuli. Am J Clin Nutr. 2012;95(4):818-24. https://doi.org/10.3945/ajcn.111. 027383

40. Markwald RR, Melanson EL, Smith MR, Higgins J, Perreault L, Eckel RH, et al. Impact of insufficient sleep on total daily energy expenditure, food intake, and weight gain. Proc Natl Acad Sci U S A. 2013;1 10(14):5695-700. https:/ doi.org/10.1073/pnas.1216951110.

41. Yang CL, Schnepp J, Tucker RM. Increased Hunger, Food Cravings, Food Reward, and Portion Size Selection after Sleep Curtailment in Women Without Obesity. Nutrients. 2019;11(3):5695-700.

42. Chaput JP. Sleep patterns, diet quality and energy balance. Physiol Behav. 2014;134:86-91. https://doi.org/10.1016/.jphysbeh.2013.09.006.

43. Nansel TR, Lipsky LM, Siega-Riz AM, Burger K, Faith M, Liu A. Pregnancy eating attributes study (PEAS): a cohort study examining behavioral and environmental influences on diet and weight change in pregnancy and postpartum. BMC Nutr. 2016;2(1). https://doi.org/10.1186/s40795-0160083-5.

44. Cox JL, Holden JM, Sagovsky R. Detection of postnatal depression. Development of the 10-item Edinburgh postnatal depression scale. Br J Psychiatry. 1987;150(6):782-6. https://doi.org/10.1192/bjp.150.6.782.

45. Cohen S, Kamarck T, Mermelstein R. A global measure of perceived stress. J Health Soc Behav. 1983;24(4):385-96. https://doi.org/10.2307/2136404.

46. Cohen S, Williamson GM. In: Spacapan S, Oskamp S, editors. Perceived stress in a probability sample of the United-States. Newbury Pk: Sage Publications Inc; 1988. p. 31-67.

47. Buysse DJ, Reynolds CF 3rd, Monk TH, Berman SR, Kupfer DJ. The Pittsburgh sleep quality index: a new instrument for psychiatric practice and research. Psychiatry Res. 1989;28(2):193-213. https://doi.org/10.1016/0165-1781 (89)90047-4.

48. Lowe MR, Butryn ML, Didie ER, Annunziato RA, Thomas JG, Crerand CE, et al. The power of food scale. A new measure of the psychological influence of the food environment. Appetite. 2009;53(1):114-8. https://doi. org/10.1016/j.appet.2009.05.016.

49. United States Census Bureau. How the Census Bureau Measures Poverty: United States Census Bureau; 2019 Available from: https://www.census.gov/ topics/income-poverty/poverty/guidance/poverty-measures.html.

50. Software SAS. Version 9.4 ed. Cary, NC. USA: SAS Institute Inc

51. Hill AJ, Weaver CF, Blundell JE. Food craving, dietary restraint and mood. Appetite. 1991;17(3):187-97. https://doi.org/10.1016/0195-6663 (91)90021-J.

52. Dye L, Warner P, Bancroft J. Food craving during the menstrual cycle and its relationship to stress, happiness of relationship and depression; a preliminary enquiry. J Affect Disord. 1995;34(3):157-64. https://doi.org/10.1 016/0165-0327(95)00013-D.

53. Blau LE, Lipsky LM, Dempster KW, Eisenberg Colman MH, Siega-Riz AM, Faith MS, et al. Women's experience and understanding of food cravings in pregnancy: a qualitative study in women receiving prenatal care at the University of North Carolina-Chapel Hill. J Acad Nutr Diet. 2020;120(5):81524. https://doi.org/10.1016/j.jand.2019.09.020.

54. Lv W, Finlayson G, Dando R. Sleep, food cravings and taste. Appetite. 2018; 125:210-6. https://doi.org/10.1016/j.appet.2018.02.013.

55. Spiegel K, Tasali E, Penev P, Van Cauter E. Brief communication: sleep curtailment in healthy young men is associated with decreased leptin levels, elevated ghrelin levels, and increased hunger and appetite. Ann Intern Med. 2004;141(11):846-50. https://doi.org/10.7326/0003-481 9-141-11-200412070-00008

56. Hanlon EC, Tasali E, Leproult R, Stuhr KL, Doncheck E, de Wit H, et al. Sleep restriction enhances the daily rhythm of circulating levels of Endocannabinoid 2-Arachidonoylglycerol. Sleep. 2016;39(3):653-64. https:// doi.org/10.5665/sleep.5546.

57. Quick Facts: Chapel Hill town, North Carolina. 2019. Available from: https:// www.census.gov/quickfacts/fact/table/chapelhilltownnorthcarolina/PST04 5219\#.

58. van Dillen $L F$, Andrade J. Derailing the streetcar named desire. Cognitive distractions reduce individual differences in cravings and unhealthy snacking in response to palatable food. Appetite. 2016;96:102-10. https:// doi.org/10.1016/j.appet.2015.09.013.

59. Van Dillen LF, Papies EK, Hofmann W. Turning a blind eye to temptation: how cognitive load can facilitate self-regulation. J Pers Soc Psychol. 2013; 104(3):427-43. https://doi.org/10.1037/a0031262. 
60. Schuz B, Schuz N, Ferguson SG. It's the power of food: individual differences in food cue responsiveness and snacking in everyday life Int J Behav Nutr Phys Act. 2015;12(1):149. https://doi.org/10.1186/s12 966-015-0312-3.

61. Lemeshow AR, Rimm EB, Hasin DS, Gearhardt AN, Flint AJ, Field AE, et al. Food and beverage consumption and food addiction among women in the Nurses' health studies. Appetite. 2018;121:186-97. https://doi.org/10.101 6/j.appet.2017.10.038

\section{Publisher's Note}

Springer Nature remains neutral with regard to jurisdictional claims in published maps and institutional affiliations.

Ready to submit your research? Choose BMC and benefit from:

- fast, convenient online submission

- thorough peer review by experienced researchers in your field

- rapid publication on acceptance

- support for research data, including large and complex data types

- gold Open Access which fosters wider collaboration and increased citations

- maximum visibility for your research: over $100 \mathrm{M}$ website views per year

At $B M C$, research is always in progress.

Learn more biomedcentral.com/submissions 